\title{
Prevalence of Ureaplasma parvum in the area of Prato, Italy
}

\author{
Tamara Brunelli, Antonella Conti, Patrizia Miglietta, Elisa Rovinati, Daniele Ferri, \\ Patrizia Casprini, Roberto Degl'Innocenti
}

\author{
Chemical Clinical Analysis and Microbiology, Santo Stefano Hospital, Prato, Italy
}

\section{Summary}

In this study, the prevalence of Ureaplasma parvum in the area of Prato (Italy) was investigated. Samples from 1197 consecutive patients were analyzed. Our results showed that the prevalence of $U$. parvum was $33.6 \%$, with a higher percentage in females than in males (40.6\% vs $9 \%)$. In addition, the prevalence of $U$. parvum was significantly lower in older patients

\section{Introduction}

Ureaplasma found in the urogenital tract are considered natural inhabitants of the lower urogenital tract of humans as they are often isolated from healthy individuals (4).

Recently, Ureaplasma have been separated into two species, $U$. urealyticum and $U$. parvum, and a number of molecular methods, able to distinguish them, have been commercialized. This new classification has been followed by a lot of studies aimed to evaluate the importance of $U$. parvum in urogenital tract infections $(2,4,8)$.

While the association of $U$. urealyticum with urogenital tract infections is well established, the role of $U$. parvum is not well known.

Correspondence: Tamara Brunelli, Laboratorio Analisi Chimico Cliniche e Microbiologia, 0spedale Santo Stefano, USL4 Prato, Via Suor Niccolina Infermiera 20, 59100 Prato (P0), Italy.

E-mail: tbrunelli@usl4.toscana.it

Key words: Urogenital; ureaplasma; infection; prevalence.

Contributions: the authors contributed equally.

Conflict of interest: the authors declare no potential conflict of interest.

Received for publication: 12 January 2015.

Accepted for publication: 29 May 2015.

(C) Copyright T. Brunelli et al., 2015

Licensee PAGEPress, Italy

Microbiologia Medica 2015; 30:4951

doi:10.4081/mm.2015.4951

This article is distributed under the terms of the Creative Commons Attribution Noncommercial License (by-nc 3.0) which permits any noncommercial use, distribution, and reproduction in any medium, provided the original author(s) and source are credited.
Nevertheless, the isolation of $U$. parvum from subjects with genitourinary tract infections as well as findings of studies on laboratory animals seem to confirm the pathogenicity of the species (4).

Data about the prevalence of U.parvum in Italy are scarce (6).

In 2012 a PCR real time method able to differentiate $U$. urealyticum and $U$. parvum has been introduced in our laboratory for the routine analysis of urogenital samples.

Aim of this study was to evaluate the prevalence of $U$. parvum in the area of Prato (Italy).

\section{Materials and Methods}

A total of 1197 patients (930 females and 267 males, age range 1581 years) attending the hospital of Prato during the year 2013 were investigated.

DNA was extracted from different samples: urine, semen (both collected in empty tubes), endocervical and uretral swabs (eSwab Copan Italia, Brescia, Italy) using EZ1-DNAextraction kit (Qiagen, Hilden, Germany) according to the manufacturer directions.

A real-time PCR method (Anyplex STI7, Seegene, Seoul, Korea) was used to detect the presence of $C$. trachomatis, $N$. gonorrhoeae, $T$. vaginalis, M. hominis, $M$. genitalium, $U$. urealyticum, $U$. parvum in the samples according to the manufacturer instructions.

Prior to extraction, all the samples were seeded on Thayer Martin (bioMérieux, Marcy-l'Étoile, France) agar and incubated at $37^{\circ} \mathrm{C}, 5 \%$ $\mathrm{CO}_{2}$ for 48 hours to search for $N$. gonorrhoeae and if positive an antimicrobial susceptibility test was performed (E-test, bio Mérieux).

\section{Results}

Four-hundred and two out of 1197 patients (33.6\%) were positive for $U$. parvum. Among these 24 (6\%) were males and 378 (94\%) females. The prevalence was significantly $(\mathrm{P}<0.0001$, chi-square) higher in females (40.6\%) than in males (9\%).

The prevalence of $U$. parvum in the different samples is shown in Table 1; the highest percentage of positivity was found in endocervical swabs.

The prevalence of U.parvum was significantly $(\mathrm{P}<0.05$, chisquare) lower in older patients (Table 2).

In addition, for the other pathogens investigated the prevalence was: 36 subjects (3\%) positive for $C$. trachomatis, $4(0.3 \%)$ for $N$. gonorrhoeae, 23 (1.9\%) for T. vaginalis, 88 (7.4\%) for M. hominis, 13 (1.1\%) for M. genitalium and $8(0.7 \%)$ for $U$. urealyticum. 


\section{Discussion}

Recent studies, performed after the separation of Ureaplasma in two species, $U$. urealyticum and $U$. parvum, have shown that $U$. parvum can be not only a commensal, but also a pathogen for the urogenital tract. For this reason we decided to introduce in our laboratory a method able to differentiate the two species. Data about the prevalence of $U$. parvum are very few and mainly from selected populations $(3,4,8)$.

We found that the prevalence of U.parvum in the area of Prato was about $34 \%$, according to data previously reported in Tuscany (6). For the other microorganisms the prevalence, in the same area, was similar to that found in the year 2011 (1). According to Jalal et al. (3) the prevalence of U.parvum was higher in women and lower in older subjects.

A limit of this study is the lack of clinical data and consequently the impossibility to correlate the presence of $U$. parvum to a clinical condition.

Data from literature suggest the usefulness of the evaluation of the presence of $U$. parvum in urogenital samples, mainly in case of infertility or preterm births. In our opinion, the laboratory should refer the presence of this microorganism and then the clinician will evaluate the opportunity to treat it.

\section{References}

1. Brunelli T, Degl'Innocenti R, Miglietta P, et al. Detection of T. vaginalis, M. hominis, M. genitalium, C. trachomatis, N. gonorrhoeae and U. urealyticum using multiplex PCR. Microbiol Med 2012; 27: 13-6.

2. Gdoura R, Kchaou W, Chaari C, et al. Ureaplasma urealyticum, Ureaplasma parvum, Mycoplasma hominis and Mycoplasma genitalium infections and semen quality of infertile men. BMC Infect Dis 2007; 7: 129-32.

3. Jalal H, Delaney A, Bentley N, et al. Molecular epidemiology of selected sexually transmitted infections. Int J Mol Epidemiol Genet 2013; 4: 167-74.

4. Kasprzykowska U, Elias J, Elias M, et al. Colonization of the lower
Table 1. Prevalence of $U$. parvum in the different materials.

\begin{tabular}{lcc} 
Material & Positive/total, $\mathbf{n}$. & $\%$ \\
Urine & $18 / 76$ & 23.7 \\
Semen & $7 / 72$ & 9.7 \\
\hline Endocervical swab & $363 / 925$ & 39 \\
Uretral swab & $14 / 124$ & 11.3 \\
\hline Total & $402 / 1197$ & 33.6 \\
\hline
\end{tabular}

Table 2. Prevalence of $U$. parvum in the different age-ranges.

\begin{tabular}{lcc} 
Age, years & Positive/total, $\mathbf{n}$. & $\%$ \\
$<25$ & $71 / 158$ & 45 \\
$25-49$ & $304 / 898$ & 34 \\
\hline$>49$ & $27 / 141$ & 19 \\
\hline
\end{tabular}

urogenital tract with Ureaplasma parvum can cause asymptomatic infection of the upper reproductive system in women: a preliminary study. Arch Gynecol Obstet 2014; 289: 1129-34.

5. Larsen B, Hwang J. Mycoplasma, Ureaplasma, and adverse pregnancy outcomes: a fresh look. Infect Dis Obstet Gynecol 2010: 521921.

6. Napoli Z, Lencioni P, Niccolai M, et al. Frequency of sexually trasmitted diseases and main methodological implications. Microbiol Med 2013; 28: 57-68.

7. Viscardi RM. Ureaplasma species: role in diseases of prematurity. Clin Perinatol 2010; 37: 393-409.

8. Yamazaki T, Matsumoto M, Matsuo J, et al. Frequency of Chlamydia trachomatis in Ureaplasma-positive healthy women attending their first prenatal visit in a community hospital in Sapporo, Japan. BMC Inf Dis 2012; 12: 82-9. 